\title{
Exhaled nitric oxide from lung periphery is increased in COPD
}

\author{
C. Brindicci*, K. Ito*, O. Resta ${ }^{\#}$, N.B. Pride*, P.J. Barnes* and S.A. Kharitonov*
}

ABSTRACT: Single constant flow exhaled nitric oxide (eNO) cannot distinguish between the sources of NO. The present study measured eNO at multiple expired flows (MEFeNO) to partition NO into alveolar (Calv,NO) and bronchial (Jaw,NO) fractions to investigate peripheral lung contribution to eNO in chronic obstructive lung disease (COPD).

MEFeNO were made in 81 subjects including 18 nonsmokers, 16 smokers and 47 COPD patients of different severity by the classification of the Global Initiative for Chronic Obstructive Lung Disease (GOLD): $0(n=14), 1(n=7), 2(n=11), 3(n=8)$ and $4(n=7)$.

COPD severity was correlated with an increased Calv,NO regardless of the patient's smoking habit or current treatment. The levels of Calv,NO (in ppb) were $1.4 \pm 0.09$ in nonsmokers, $2.1 \pm 0.1$ in smokers categorised as GOLD stage 0 (smokers-GOLDo), $3.3 \pm 0.18$ in GOLD1-2 and $3.4 \pm 0.1$ in GOLD3-4. Jaw,NO levels $\left(\mathrm{pL} \cdot \mathrm{s}^{-1}\right)$ were higher in nonsmokers than smokers-GOLDo (716.2 \pm 33.3 versus $464.7 \pm 41.8)$, GOLD3-4 (609.4 \pm 71 ). Diffusion of NO in the airways (Daw,NO $\mathrm{pL} \cdot \mathrm{ppb}^{-1} \mathrm{~s}^{-1}$ ) was higher $(p<0.05)$ in GOLD3-4 than in nonsmokers $(15 \pm 1.2$ versus $11 \pm 0.5)$ and smokers-GOLDo $(11.6 \pm 0.5)$. MEFeNO measurements were reproducible, free from day-to-day and diurnal variation and were not affected by bronchodilators.

In conclusion, chronic obstructive pulmonary disease is associated with elevated alveolar nitric oxide. Measurements of nitric oxide at multiple expired flows may be useful in monitoring inflammation and progression of chronic obstructive pulmonary disease, and the response to anti-inflammatory treatment.

KEYWORDS: Chronic obstructive pulmonary disease, exhaled nitric oxide, multiple expiratory flow, small airway inflammation

ingle expiratory flow exhaled nitric oxide (eNO) measurements are simple, highly reproducible [1], have been used to monitor larger airway inflammation in asthma research [2], and are now moving into clinical practice [3]. However, small airways and lung parenchyma are the predominant sites of inflammation in patients with chronic obstructive pulmonary disease (COPD) [4]. Progression of COPD is associated with the accumulation of inflammatory mucous exudates in the lumen and infiltration of the small airway wall by inflammatory cells [4]. There is a high level of expression of inducible NO synthase (iNOS) presence in sputum macrophages [5], alveolar walls, small airway epithelium and vascular smooth muscle of COPD patients $[5,6]$. In patients with COPD this may result in an increased production of $\mathrm{NO}$ and NO-related species in the lung periphery, which through the function of peroxynitrite may amplify the inflammation and lead to inhaled corticosteroid (ICS) resistance, particularly as the disease becomes more severe [7].
The current single expiratory technique measures predominantly larger airway-derived $\mathrm{NO}$ and may only partially reflect peripheral inflammation $[8,9]$. eNO is often in the normal range or even reduced in moderate COPD [10], probably due to down-regulation of endothelial $\mathrm{NO}$ synthase (eNOS) [11] and iNOS [12] by cigarette smoke.

Recently, methods for measuring eNO at multiple expiratory flows (MEFeNO) $[13,14]$ have been used to detect elevated levels of alveolar $\mathrm{NO}$ in fibrosing alveolitis [13], asthma [15, 16] and COPD [17] leading to the refinement of analytical methods to discriminate exhaled NO sources in the lung [18].

There is agreement that a simple two-compartment model, which is based on MEFeNO, can adequately represent the marked dependence of eNO on exhalation flow $[19,20]$. Three flowindependent NO exchange parameters can describe the airway compartment: airway NO diffusing capacity $\left(D_{\mathrm{aw}, \mathrm{NO}}\right)$ and either the
AFFILIATIONS

*Section of Airway Disease, National Heart and Lung Institute, Imperial College, London, UK. \#Institute of Respiratory Disease, University of Bari, Bari, Italy.

CORRESPONDENCE

S.A. Kharitonov

Section of Airway Disease

National Heart and Lung Institute

Imperial College

Dovehouse Street

London SW3 6LY

UK

Fax: +442073518126

E-mail:s.kharitonov@imperial.ac.uk

Received:

November 012004

Accepted after revision:

March 262005

SUPPORT STATEMENT

This work was supported by the Section of Airway Disease, National Heart and Lung Institute, Imperial College, London, UK.

European Respiratory Journal Print ISSN 0903-1936 Online ISSN 1399-3003 
maximum airway wall NO flux, also known as the airway wall $\mathrm{NO}$ concentration $(\mathrm{Jaw}, \mathrm{NO})$, and the alveolar region or steadystate alveolar NO concentration (Calv,NO) [18]. This model is able, to a certain degree, to partition eNO into an airway source that is reduced by ICS [21] and an alveolar source that is not affected by this treatment [22]. This discriminative analysis may be of particular interest in COPD due to its greater peripheral distribution of inflammation that appears to be relatively resistant to ICS.

The current authors have previously reported that MEFeNO differentiates between bronchial and alveolar inflammation in patients with asthma and COPD, and Calv,NO is increased in COPD patients [23]. The aim of the present study was to validate the MEFeNO measurements in COPD patients of varying severity, and to investigate the effects of smoking history and treatment on these measurements.

\section{METHODS}

\section{Subjects}

MEFeNO was measured in 81 subjects, comprising 18 nonsmokers, 16 smokers, 14 with Global Initiative for Chronic Obstructive Lung Disease (GOLD) stage 0 (at risk), seven with stage 1 (mild), 11 with stage 2 (moderate), eight with stage 3 (severe) and seven with stage 4 (very severe) COPD, according to the GOLD classification (table 1).

\section{Study design}

All subjects underwent MEFeNO measurements between 09:00-10:00 h, consisting of two exhalations at each flow, which is sufficient to obtain reproducible NO results [1]. In addition, the reproducibility and diurnal variation of MEFeNO measurements were examined in 36 subjects (nine nonsmokers, 12 smokers-GOLD0, 10 with GOLD stage 1-2 and five with GOLD stage 3-4) by measuring their MEFeNO t.i.d. between 09:00-10:00, 12:00-13:00 and 15:00-16:00 h. Day-today variation, as well as the diurnal variation, of MEFeNO was assessed in eight COPD patients (GOLD2) when their MEFeNO was measured between 09:00-10:00, 12:00-13:00 and 15:0016:00 h on two consecutive days. MEFeNO levels and forced expiratory volume in one second (FEV1) were also measured before and $45 \mathrm{~min}$ after ipratropium bromide ( $40 \mu \mathrm{g})$ given via a spacer in randomly allocated patients to investigate any potential effect of air calibre changes on Calv,NO, Jaw,NO and Daw,NO. All patients refrained from using bronchodilators before the measurements. The effects of smoking and current treatment with ICS were also assessed by comparing values in current versus ex-smokers and patients who were treated with and without inhaled steroids. The effect of ambient $\mathrm{NO}$ on Calv,NO was studied in five COPD patients (GOLD0-1) whose MEFeNO measurements were made after either one inhalation of NO-free air from the analyser (standard operating

\section{TABLE 1 Subject characteristics}

\begin{tabular}{|c|c|c|c|c|}
\hline Variables & Nonsmokers & Smokers-GOLD 0 & GOLD 1-2 & GOLD 3-4 \\
\hline Subjects $n$ & 18 & 30 & 18 & 15 \\
\hline Sex M:F & $8: 10$ & $16: 14$ & $10: 8$ & $9: 6$ \\
\hline Pack-yrs ex-smokers & & $3(32 \pm 3)$ & $7(43 \pm 3)$ & $12(50 \pm 7)$ \\
\hline Pack-yrs current smokers & & $27(35 \pm 2)$ & $11(48 \pm 4)$ & $3(40 \pm 5)$ \\
\hline FVC L & $4(3.7-4.4)$ & $4.4(3.9-4.7)$ & $3.9(3.2-4.5)$ & $2.8(2.5-3.2)$ \\
\hline FVC $\%$ pred & $101(96-107)$ & $106(101-110)$ & $101(85-120)$ & 80 (70-96) \\
\hline FEV $_{1 / \text { FVC } \% \text { pred }}$ & $86(82-90)$ & $80(78-81)$ & $57(48-66)$ & $36(29-40)$ \\
\hline PEF \% pred & & $101(94-106)$ & $74(61-88)$ & $41(37-45)$ \\
\hline RV \% pred & & $116(92-140)$ & $140(122-159)$ & $195(155-231)$ \\
\hline TLC \% pred & & $109(97-121)$ & $113(99-127)$ & $125(110-139)$ \\
\hline MEF $75 \%$ pred & & $85(62-108)$ & $50(32-66)$ & $9.9(6.8-13)$ \\
\hline MEF $50 \%$ pred & & $61(31-90)$ & $32(20-43)$ & $7.3(5-10)$ \\
\hline MEF $25 \%$ pred & & $45(14-73)$ & $26(14-38)$ & $6.7(3.6-8)$ \\
\hline SABA & & & 6 & 7 \\
\hline LABA & & & 5 & 10 \\
\hline LABA+ICS & & & 6 & 12 \\
\hline Theophylline & & & & 4 \\
\hline
\end{tabular}

Data are presented as mean \pm SEM, mean (95\% confidence intervals) or n. GOLD: Global Initiative for Chronic Obstructive Lung Disease; M: male; F: female; FEV1: forced expiratory volume in one second; \% pred: per cent predicted; FVC: forced vital capacity; PEF: peak expiratory flow; RV: residual volume; TLC: total lung capacity; TL,CO: transfer factor of the lung for carbon monoxide; $K \mathrm{CO}$ : carbon monoxide transfer coefficient; $V_{\mathrm{A}}$ : alveolar volume; MEF 75, 50, 25: mean forced expiratory flow during the 75,50 and $25 \%$ of the FVC; SABA: short-acting $\beta_{2}$ agonists; LABA: long-acting $\beta_{2}$ agonists; ICS: inhaled corticosteroids. 
procedure for the single exhalation eNO and MEFeNO measurements in the present authors' laboratory) versus five consecutive breaths of NO-free air made in two sessions separated by $3 \mathrm{~h}$ with recording of ambient NO.

None of the subjects studied had recent (4 weeks prior the study) upper respiratory tract infections, chest infection or COPD exacerbations. All of the subjects were advised not to consume any nitrite-enriched food (i.e. spinach) before the study visits. The study was approved by the Ethics Committee of the Royal Brompton Hospital and Harefield NHS Trust (London, UK) and all the patients gave written informed consent.

\section{Lung function}

Measurements of FEV1 and FEV1/forced vital capacity (FVC) were made with a dry spirometer (Vitalograph-S; Vitalograph Ltd, Buckingham, UK) which met American Thoracic Society (ATS) standards. Lung volumes and carbon monoxide gas transfer were measured with a Jaeger Master Lab Compact Transfer (Erich Jaeger Ltd, Hoechberg, UK), as described previously [20].

\section{MEFeNO measurements}

Standardised single eNO (expiratory flow $50 \mathrm{~mL} \cdot \mathrm{s}^{-1}$ ) was measured by a chemiluminescence analyser (NIOX ${ }^{\circ}$; Aerocrine AB, Stockholm, Sweden), as described previously [1]. MEFeNO was measured at expiratory rates 10, 100, 200 and $260 \mathrm{~mL} \cdot \mathrm{s}^{-1}$ by applying resistors of $10,100,200$ and $300 \mathrm{~cm}$ $\mathrm{H}_{2} \mathrm{O} \mathrm{mL} \cdot \mathrm{s}^{-1}$ to create and maintain the target flow rates. MEFeNO was measured using a vital capacity manoeuvre performed in duplicate [1] to collect plateau NO concentrations. Mean eNO at each expiratory flow was calculated by the analyser during an NO plateau of $\geqslant 3 \mathrm{~s}$ with $\mathrm{NO}$ variability within $10 \%$ of the plateau or $\pm 1 \mathrm{ppb}$ [1]. The patients inhaled NO-free air from the analyser and then exhaled against different linear resistors. The exhalation time was $20 \mathrm{~s}$ for $10 \mathrm{~mL} \cdot \mathrm{s}^{-1}, 10 \mathrm{~s}$ for 50 and $100 \mathrm{~mL} \cdot \mathrm{s}^{-1}$, and $6 \mathrm{~s}$ for 200 and $260 \mathrm{~mL} \cdot \mathrm{s}^{-1}$. The second manoeuvre (to estimate the effect of ambient $\mathrm{NO}$ on $\mathrm{Calv}, \mathrm{NO}$ ) involved five breaths of NO-free air from the analyser followed by a standard vital capacity manoeuvre. Jaw,NO, Calv,NO, and Daw,NO were calculated as previously described (Appendix 1) [18, 24].

\section{Statistical methods}

The correlation between Calv,NO and FEV1 and other parameters was determined using the Spearman rank correlation test. Intra-class correlation coefficient (ICC; table 2) was used for each flow separately for all the subjects. Nonparametric tests were applied as the distribution of these variables was not known and there were insufficient data for normal distribution analysis. Data were expressed as mean \pm SD and/or \pm SEM, or mean ( $95 \%$ confidence intervals $(\mathrm{CI})$ ). ANOVA was performed using the Kruskall-Wallis test for multiple comparisons. For comparison of two groups, the Mann-Whitney U-test after Bonferroni correction was used. Reproducibility was assessed by the pooled SD and Bland-Altman test. A value of $p<0.05$ was considered statistically significant.

\section{RESULTS}

MEFeNO: repeatability, reproducibility and diurnal variation The mean pooled SD1 of all measurements was $0.32 \pm 0.60 \mathrm{ppb}$ (table 2) and MEFeNO measurements were highly reproducible (fig 1). Pooled SD analysis of all the subjects at the flows 10, 50, 100,200 and $260 \mathrm{~mL} \cdot \mathrm{s}^{-1}$ was the highest at the lowest exhalation flow of $10 \mathrm{~mL} \cdot \mathrm{s}^{-1}$ (table 2). Calv,NO and other measurements (data not shown) made at different visits and time points were highly reproducible and there was no significant day-to-day or diurnal variation (fig. 2).

\section{Effect of ambient NO and NO-free air inhalation on MEFeNO}

There was no effect of ambient $\mathrm{NO}$ on Calv,NO, Jaw,NO or Daw,NO (data not shown). There was no difference in Calv,NO measured after one $(2.0 \pm 1.13 \mathrm{ppb}$; $95 \%$ CI $0.63-3.43 \mathrm{ppb}$; ambient NO $72 \pm 27 \mathrm{ppm}$; 95\% CI 38-106 ppm) versus five consecutive breaths $(2.0 \pm 1.45 \mathrm{ppb}$; $95 \%$ CI $0.20-3.80 \mathrm{ppb}$; ambient NO $64 \pm 29$ ppm; $95 \%$ CI 28-100 ppm) of NO-free air.

\section{Effect of bronchodilator}

There was no effect of the iptratropium bromide on the Calv,NO, Jaw,NO, Daw,NO and patient's lung function (fig. 2).

\section{Effect of smoking and ICS on Calv,NO, Jaw,NO and Daw,NO}

There was no difference in either $\mathrm{Calv}, \mathrm{NO}$ or $\mathrm{Daw}, \mathrm{NO}$ between the current and ex-smokers COPD patients $(3.2 \pm 0.2$ versus $3.4 \pm$ $0.1 \mathrm{ppb}$ and $18.1 \pm 1.4$ versus $13.5 \pm 0.9 \mathrm{pL} \cdot \mathrm{ppb}^{-1} \mathrm{~s}^{-1}$, respectively;

TABLE 2 Exhaled NO at multiple expiratory flows measurements at different exhalation flows in the groups of subjects studied

\begin{tabular}{lcccccc} 
& ICC & Pooled sD1 & Nonsmokers & Smokers-GOLDo & GOLD1-2 & GOLD3-4 \\
\hline $\begin{array}{l}\text { Subjects n } \\
\text { eNO expiratory rate } \mathbf{~} \mathbf{m} \cdot \mathbf{s}^{-1}\end{array}$ & & & & 30 & 18 & \\
10 & & & & & & \\
50 & $0.977^{* *}$ & $0.84 \pm 1.5$ & $43.5 \pm 7.3(39.8-47.1)$ & $28.1 \pm 13.4(23.1-33.1)$ & $33.2 \pm 22.1(22.2-42.2)$ & $31.1 \pm 10.8(25.1-37.1)$ \\
100 & $0.993^{* *}$ & $0.30 \pm 0.36$ & $13.5 \pm 2.4(12.2-14.6)$ & $10.1 \pm 4.3(8.3-11)$ & $14.6 \pm 7.3(10.9-18.2)$ & $15.2 \pm 5.7(12.0-18.4)$ \\
200 & $0.992^{* *}$ & $0.18 \pm 0.19$ & $8.0 \pm 1.3(7.4-8.6)$ & $6.5 \pm 2.4(5.5-7.4)$ & $9.1 \pm 3.8(7.2-11.1)$ & $9.2 \pm 2.6(7.6-10.5)$ \\
260 & $0.989^{* *}$ & $0.12 \pm 0.13$ & $5.2 \pm 0.7(4.8-5.5)$ & $4.7 \pm 1.2(4.1-5.2)$ & $6.6 \pm 2.1(5.6-7.7)$ & $6.7 \pm 1.6(5.8-7.5)$ \\
Pooled sD1,total & $0.988^{* *}$ & $0.11 \pm 0.13$ & $4.1 \pm 0.6(3.8-4.4)$ & $3.9 \pm 1.1(3.4-4.3)$ & $5.6 \pm 1.6(4.8-6.4)$ & $5.8 \pm 1.3(5.0-6.4)$ \\
\hline
\end{tabular}

Data are presented as mean \pm SD (95\% confidence intervals). ICC: intra-class correlation coefficient on each flow in all subjects (Pearson correlation coefficient); pooled SD1: pooled SD on each flow in all subjects; GOLD: Global Initiative for Chronic Obstructive Lung Disease; eNO: exhaled nitric oxide; pooled SD1,total: pooled SD for total 360 observations (eNO of 72 subjects $\times 5$ exhalation flows $=360$ ). ${ }^{* *}: \mathrm{p}<0.01$ versus pooled SD1,total \pm SD. ${ }^{*}: \mathrm{n}=405$. 


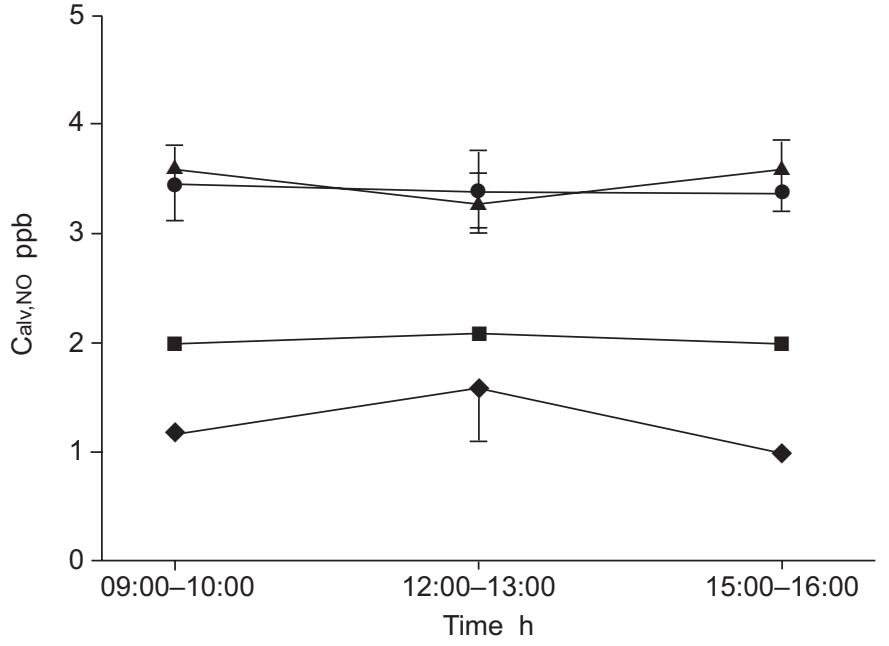

FIGURE 1. Diurnal variation of alveolar nitric oxide concentration (Calv,NO) values in 38 subjects measured between 09:00-10:00, 12:00-13:00 and 15:0016:00 h. : healthy nonsmokers; - smokers-Global Initiative for Chronic Obstructive Pulmonary Disease (GOLD) stage 0; $\mathbf{\Delta}$ : GOLD stage 1-2; $\bullet$ : GOLD stage $3-4$.
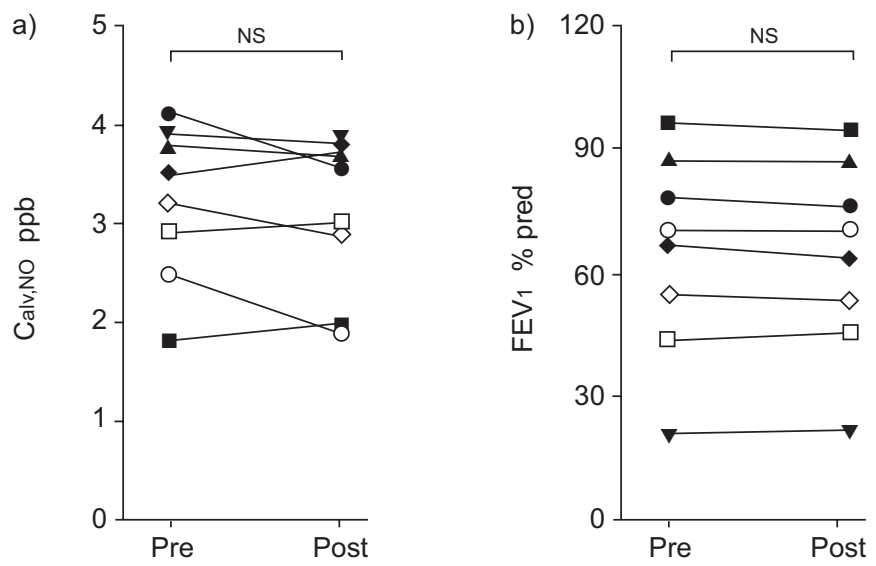

FIGURE 2. Effect of iptratropium bromide $(40 \mu \mathrm{g})$ on a) alveolar nitric oxide concentration (Calv,NO) and b) forced expiratory volume in one second (FEV1) values in eight chronic obstructive pulmonary disease patients measured after 45 minutes. Ns: nonsignificant. Each symbol represents a different subject.

fig. 3). Current COPD smokers, however, had lower Jaw,NO $\left(497 \pm 88.1 \mathrm{pL} \cdot \mathrm{s}^{-1}\right)$ than ex-smokers $\left(711 \pm 81, \mathrm{pL} \cdot \mathrm{s}^{-1} ; \mathrm{p}<0.01\right)$. Although there was a trend towards a lower Jaw,NO in COPD patients taking ICS, this was not significant. ICS did not have any effect on Calv,NO (no ICS $3.4 \pm 0.1 \mathrm{ppb}$ versus treatment with ICS $3.3 \pm 0.2 ; \mathrm{p}>0.05$ ), nor on Daw,NO (no ICS $14 \pm 0.1$ versus treatment with ICS $17 \pm 1.4 \mathrm{pL} \mathrm{ppb}^{-1} \mathrm{~s}^{-1}, \mathrm{p}>0.05$; fig. 3).

\section{COPD severity and Calv,NO, Jaw,NO and Daw,NO}

There was a significant increase in Calv,NO in COPD patients (fig. 4a; table 3), and significant negative correlation between Calv,NO and FEV1 $(\mathrm{r}=-0.6, \mathrm{p}<0.0001)$, in COPD patients and normal smokers (fig. 5). The levels of Jaw,NO (fig. 4b; table 3) were lower in smokers-GOLD0 and COPD GOLD3-4 than in healthy nonsmoking control subjects. The levels of Daw,NO

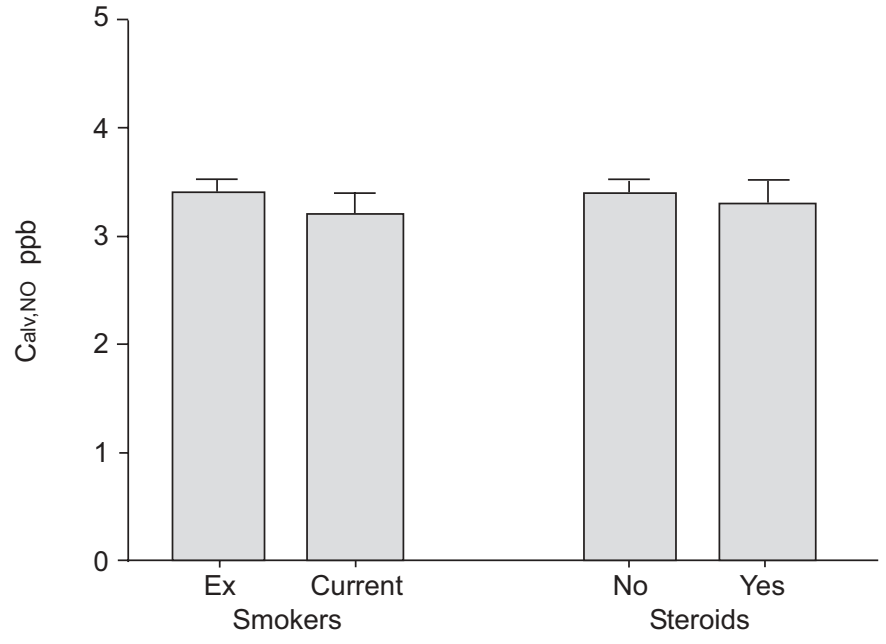

FIGURE 3. Effect of smoking and inhaled corticosteroids on the alveolar nitric oxide concentration (Calv,NO) in chronic obstructive pulmonary disease patients.

(fig. 4c; table 3) were increased in COPD patients compared with smokers and healthy controls. A weak negative correlation $(\mathrm{r}=-0.4, \mathrm{p}=0.006)$ was found between the Daw,NO and FEV1 across all COPD and smoking subjects. No correlation was found between Jaw,NO and FEV1 or between Calv,NO, Jaw,NO and Daw,NO and alveolar volume, transfer of the lung for carbon monoxide or mean forced expiratory flow during the $25 \%$ of the FVC (data not shown).

\section{DISCUSSION}

The main finding of the present study is that the elevated eNO in COPD patients is derived, predominantly, from the periphery of the lung but is unaffected by smoking, bronchodilators or ICS. The current authors have also shown that MEFeNO measurements are highly reproducible, free of diurnal variation and can be applied in COPD patients of differing severity.

\section{Reproducibility and variability}

Identifying the variability of this novel technique is important for the potential clinical utility of the MEFeNO parameters to document longitudinal changes in COPD. The high level of reproducibility of MEFeNO measurements (ICC 0.96) was similar to the high reproducibility of the ATS-standardised eNO measurements (ICC 0.99) [1]. The variability of MEFeNO was not greater in more severe COPD patients, despite the fact that some individuals found it difficult to complete the high exhalation flow manoeuvre $\left(260 \mathrm{~mL} \cdot \mathrm{s}^{-1}\right)$ before the required $6 \mathrm{~s}$ exhalation time. The most difficult flow to maintain was $10 \mathrm{~mL} \cdot \mathrm{s}^{-1}$ (pooled SD1 $0.8 \pm 1.4 \mathrm{ppb}$ ), because of the long duration of exhalation (20 s), but this was unrelated to the degree of airway obstruction. The lack of diurnal variability of the MEFeNO in COPD was expected considering the nature of the disease and previously published data demonstrating no diurnal variation of $\mathrm{Calv}, \mathrm{NO}$ and Jaw,NO in either asthmatics or patients with fibrosing alveolitis [13].

\section{Effect of ambient NO}

Ambient NO (0-138 ppm) did not influence Calv,NO (the lowest amongst the other $\mathrm{NO}$ parameters measured by 

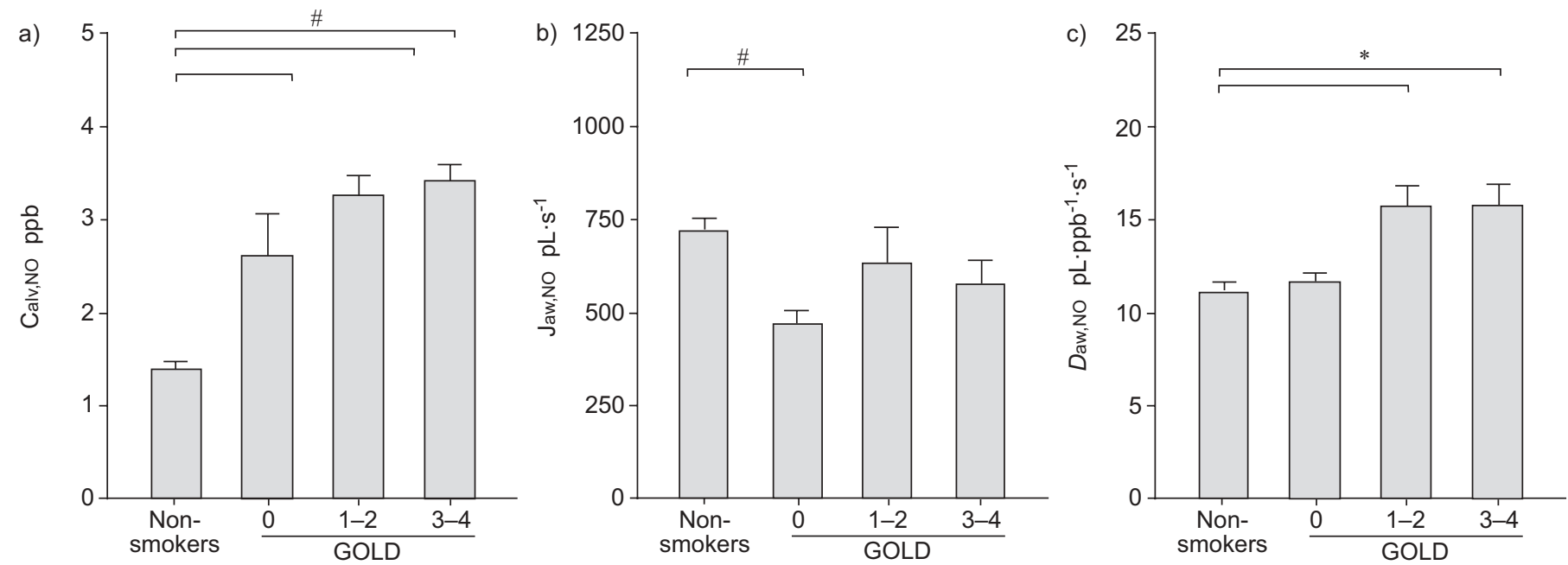

FIGURE 4. a) Alveolar nitric oxide concentration (Calv,NO), b) airway wall NO concentration (Jaw,NO) and c) airway NO diffusing capacity (Daw,NO) in nonsmokers, smokers and chronic obstructive pulmonary disease patients of different severity according to the classification of the Global Initiative for Chronic Obstructive Lung Disease (GOLD). *: $p<0.05 ;{ }^{*}: p<0.0001$

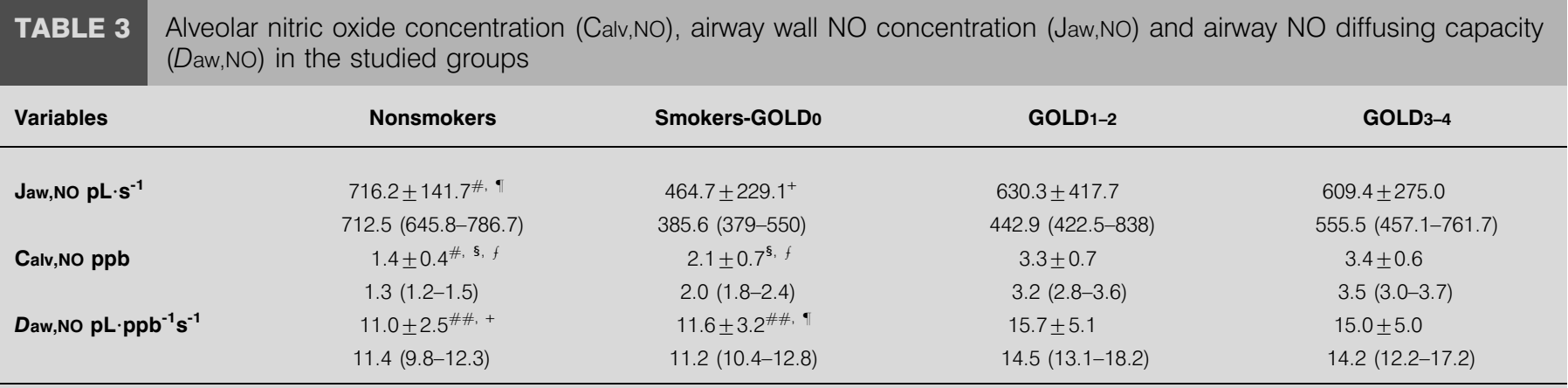

Data are presented as mean \pm SD and median (95\% confidence intervals). GOLD: Global Initiative for Chronic Obstructive Lung Disease. ${ }^{\#}: p<0.0001$ versus smokers with GOLD stage $0 ;{ }^{\top}: p<0.05$ versus smokers with GOLD stage $0 ;{ }^{+}: p<0.05$ versus patients with GOLD stage $3-4 ;{ }^{\varsigma}: p<0.0001$ versus patients with GOLD stage $1-2 ;{ }^{f}$ : $p<0.0001$ versus patients with GOLD stage $3-4 ; \# \#: p<0.05$ versus patients with GOLD stage $1-2$.

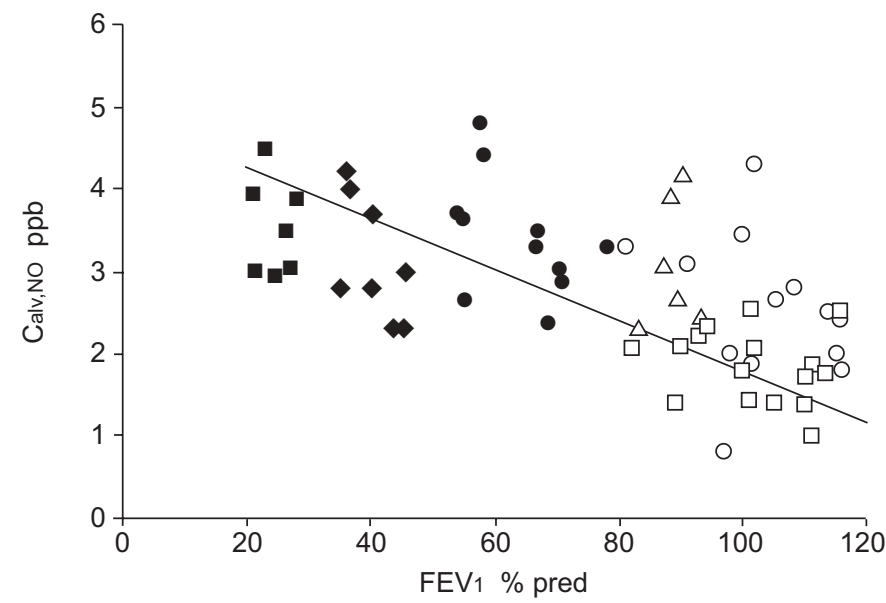

FIGURE 5. Association between the alveolar nitric oxide concentration $(\mathrm{Calv}, \mathrm{NO})$ and forced expiratory volume in one second (FEV1) per cent predicted (\% pred) for all smokers and chronic obstructive pulmonary disease patients $(r=0.6$; $\mathrm{p}<0.0001)$. $\square$ : smokers; $\bigcirc$ : Global Initiative for Chronic Obstructive Lung Disease (GOLD); $\triangle$ : GOLD1; •: GOLD2; : GOLD3; $\mathbf{a}:$ GOLD4.
MEFeNO), and a single inhalation versus five inhalations of NOfree air had the same effect on Calv,NO. This gives further support for the development of portable NO analysers capable of the MEFeNO measurements, so that Calv,NO might be monitored by COPD patients at home in the future.

\section{Effect of bronchodilators}

Although no changes were seen in Calv,NO and other NO parameters or FEV1 after inhalation of ipratropium bromide that may reduce air trapping, it still too early to say to what extent Calv,NO is related to small airway obstruction and/or to small airway inflammation. Perhaps, both of these factors contribute to elevated levels of Calv, NO in COPD, but their contribution may only be determined once effective antiinflammatory treatments are developed.

\section{Effect of smoking}

There was no difference in Calv,NO between current smokers and ex-smokers, although Jaw,NO was reduced, thus, confirming previous studies $[8,13]$ which show a reduced eNO using the 
single exhalation technique. An acute and transient (1-5 min) increase in Jaw,NO has been previously reported after smoking a cigarette [13]. This is most likely to be due to release of inhaled NO from haemoglobin and/or nitrosothiols. The reduction in Jaw,NO and eNO using the single exhalation technique [8] is likely to be due to down-regulation of both eNOS [11] and iNOS in lung epithelial cells of large airways [12].

In contrast, the increase in Calv,NO in COPD patients (that was almost twice as high as in smokers) is mainly from the peripheral lung and is most likely derived from iNOS in macrophages and alveolar walls that are not directly affected by smoking [6]. The present authors speculate that the elevated $\mathrm{Calv}, \mathrm{NO}$ in COPD and its relation to the disease severity may be a manifestation of peripheral lung inflammation involving alveolar walls and small airways. Smoking may trigger this inflammatory cascade, but does not have a direct effect on the source of Calv,NO.

\section{Effect of corticosteroids}

The role of ICS in COPD is under scrutiny, as there is little evidence of their effect on various inflammatory markers in COPD. The current study has shown no effect of ICS on Calv,NO or Daw,NO and a rather small reduction in Jaw,NO. This is markedly different from asthma, where Daw,NO and Jaw,NO, but not Calv,NO are significantly reduced by ICS [15, 22, 25]. A short course of oral steroids, but not the inhaled steroids, was able to reduce Calv,NO in patients with moderate asthma [26] suggesting that inhaled steroids may not reach inflammation in peripheral airways. This indicates an important advantage of MEFeNO measurements in COPD for monitoring the inflammatory process that is clearly different from asthma.

\section{COPD severity}

The progression of COPD from GOLD stage 0 to GOLD stage 4 is most strongly associated with thickening of the wall of small airways by a repair or remodelling process [4], and with the intensity of the inflammation response in the walls of these airways. The present authors speculate that the severityrelated increase of the Calv,NO in COPD may reflect this mechanism of disease progression. Low Jaw,NO and high Calv,NO may have different pathophysiological effects and roles, and, therefore, may be pharmacologically corrected using different drugs, including iNOS inhibitors or NOS donors [7]. The present study has shown a significant correlation between $\mathrm{Calv}, \mathrm{NO}$ and both FEV1 and FEV1/FVC ratio, which was not seen in either healthy subjects [27] or in mild asthmatics $[15,26]$, suggesting that Calv,NO in COPD patients may reflect peripheral inflammation and remodelling resulting in increased peripheral resistance. Calv,NO might be an early and simple marker to diagnose early stages of peripheral inflammation in COPD. Therefore, even COPD and some asthmatic patients may have a similar degree of fixed airway obstruction. The nature of the airway and lung parenchyma inflammation in these diseases is different [28] and elevated Calv,NO may reflect the predominant small airway inflammation in COPD.

The elevated levels of Calv,NO in the present study were similar to the levels reported by HoGMAN et al. [17], and may indicate accumulation of $\mathrm{NO}$ and NO-related species in the periphery of the lungs, as high iNOS expression has been reported in macrophages [5], alveolar walls, small airway epithelium and vascular smooth muscles of COPD patients [5, 6]. Significantly higher numbers of iNOS-positive cells in alveolar walls in more severe COPD patients [29] may explain the high levels of Calv,NO in GOLD3-4. Interestingly, the Calv,NO was most elevated in patients with GOLD1-2 and GOLD3-4, but there was no significant difference between these two groups. Although the number of patients in the current study with stage GOLD4 is small because of the difficulty in performing the manoeuvre, this may reflect the fact that patients with severe emphysema show a lower percentage of iNOS-positive alveolar macrophages than patients with milder disease [30]. In fact, some of the stage GOLD2 patients had Calv,NO levels similar to those of more severe patients.

Thickening and fibrosis of the airway walls and increased production of mucus might be expected to decrease $D$ aw,NO in COPD patients by increasing the diffusion distance for NO. However, the current authors found higher Daw,NO in COPD patients compared with smokers-GOLDo and healthy nonsmokers. The inflammation may increase the surface area of airways producing $\mathrm{NO}$ by stimulating iNOS and increasing the Daw,NO. Consumption of NO is also a possibility; in vivo NO reacts with several substrates like oxygen, protein thiols (glutathione) and superoxide. In COPD there are an increased number of neutrophils producing toxic radicals, including superoxide, which can react quickly with $\mathrm{NO}$ to form peroxynitrite, nitrite and nitrate.

\section{Advantages and limitations}

A major advantage of this noninvasive and relatively simple approach of eNO analysis is to monitor eNO, as a marker of inflammation, derived from the lung periphery and to assess the main site of inflammation in COPD. There are, however, potential sources of error in the measurements or interpretation of MEFeNO values that need to be considered. The structural changes in COPD comprise mucoid impaction and atelectasis, often coexisting bronchiectasis, bronchial dilatation and bronchial wall thickening. Bronchoconstriction, small airways obstruction, air trapping, airway hypersecretion and accumulation of inflammatory mucous exudates in the lumen of small airway may result in an overestimation of Calv,NO production and bronchial wall thickening and airway hypersecretion may distort Daw,NO values. Presently, the weakness of current mathematical models, which are used to calculate the NO parameters is that these structural abnormalities are not yet integrated into the analysis. Another factor which may affect MEFeNO in COPD patients of different severity is the surface area of the lung which participates in the exchange process. However, no significant correlation was found between NO exchange parameters and alveolar volume in COPD patients, nor in normal subjects. Finally, the current model that was used in the current authors' calculations assumes that $\mathrm{NO}$ is nonreactive. It may be speculated that increased production of superoxide in the airway by neutrophils lowers the NO concentration which may be left unaccounted for in a two-compartment model.

\section{Conclusion}

The present authors conclude that measurements of exhaled nitric oxide at multiple expired flows to determine alveolar 
nitric oxide concentration reflect inflammation in the peripheral lung of patients with chronic obstructive pulmonary disease; alveolar nitric oxide concentration is not affected by inhaled corticosteroid therapy or smoking and, thus, may provide valuable additional information for assessing the inflammatory process and its response to different therapies.

\section{APPENDIX 1. EQUATIONS FOR CALCULATING EXHALED NITRIC OXIDE CONCENTRATIONS}

The equation governing the model [24, 27, 31] predicts the exhaled concentration (Cexh, $\mathrm{ppb}$ ) as a function of the residence time (tres) of each differential bolus of air in the airway compartment, the volume of the airway compartment (Vair) and the remaining three parameters (Jaw,NO, Daw,NO, Calv,NO).

1. Cexh $(t)=($ Calv,NO-Jaw,NO $/ D a w, N O) \times \mathrm{e} \times(D$ aw,NO $/$ Vair $\times t$ res $)$ $+(\mathrm{Jaw}, \mathrm{NO} / \mathrm{Daw}, \mathrm{NO})$

Mathematical identification of the parameters has been previously described in detail: Calv,NO and Jaw,NO can be estimated by using the slope and the intercept of a resulting linear relationship by measuring $V \mathrm{NO}$ (elimination rate of nitric oxide (NO) from the breath during exhalation) at multiple constant exhalation flow rates $(V E)$ :

\section{2. $V \mathrm{NO}=\mathrm{Calv}, \mathrm{NO} \times V \mathrm{E}+\mathrm{Jaw}, \mathrm{NO}$}

Once Calv,NO and Jaw,NO have been calculated, Microsoft Excels' solver tool was used to estimate Daw,NO according to the equation.

\section{ACKNOWLEDGEMENTS}

The authors would like to acknowledge the technical help of M. Carlson (Aerocrine AB, Stockholm, Sweden) and B. Jonsson (Stockholm, Sweden).

\section{REFERENCES}

1 Kharitonov SA, Gonio F, Kelly C, Meah S, Barnes PJ. Reproducibility of exhaled nitric oxide measurements in healthy and asthmatic adults and children. Eur Respir J 2003; 21: 433-438.

2 Kharitonov SA, Barnes PJ. Exhaled markers of pulmonary disease. Am J Respir Crit Care Med 2001; 163: 1693-1722.

3 Kharitonov SA. Exhaled markers of inflammatory lung diseases: ready for routine monitoring? Swiss Med Wkly 2004; 134: 175-192.

4 Hogg JC, Chu F, Utokaparch S, et al. The nature of smallairway obstruction in chronic obstructive pulmonary disease. N Engl J Med 2004; 350: 2645-2653.

5 Ichinose M, Sugiura H, Yamagata S, Koarai A, Shirato K. Increase in reactive nitrogen species production in chronic obstructive pulmonary disease airways. Am J Respir Crit Care Med 2000; 162: 701-706.

6 Paska C, Maestrelli P, Formichi B, et al. Increased expression of inducible NOS in peripheral lung of severe COPD patients. Eur Respir J 2002; 20: Suppl. 38, 95s.

7 Kharitonov SA, Barnes PJ. Nitric oxide, nitrotyrosine, and nitric oxide modulators in asthma and chronic obstructive pulmonary disease. Curr Allergy Asthma Rep 2003; 3: 121-129.
8 Maziak W, Loukides S, Culpitt SV, Sullivan P, Kharitonov SA, Barnes PJ. Exhaled nitric oxide in chronic obstructive pulmonary disease. Am J Respir Crit Care Med 1998; 157: 998-1002.

9 Montuschi P, Kharitonov SA, Barnes PJ. Exhaled carbon monoxide and nitric oxide in COPD. Chest 2001; 120: 496-501.

10 Clini E, Bianchi L, Vitacca M, Porta R, Foglio K, Ambrosino N. Exhaled nitric oxide and exercise in stable COPD patients. Chest 2000; 117: 702-707.

11 Hutchison SJ, Sievers RE, Zhu BQ, et al. Secondhand tobacco smoke impairs rabbit pulmonary artery endothelium-dependent relaxation. Chest 2001; 120: 2004-2012.

12 Hoyt JC, Robbins RA, Habib M, et al. Cigarette smoke decreases inducible nitric oxide synthase in lung epithelial cells. Exp Lung Res. 2003; 29: 17-28.

13 Lehtimaki L, Turjanmaa V, Kankaanranta H, Saarelainen S, Hahtola P, Moilanen E. Increased bronchial nitric oxide production in patients with asthma measured with a novel method of different exhalation flow rates. Ann Med 2000; 32: 417-423.

14 Lehtimaki L, Kankaanranta H, Saarelainen S, et al. Extended exhaled NO measurement differentiates between alveolar and bronchial inflammation. Am J Respir Crit Care Med 2001; 163: 1557-1561.

15 Silkoff PE, Sylvester JT, Zamel N, Permutt S. Airway nitric oxide diffusion in asthma. Role in pulmonary function and bronchial responsiveness. Am J Respir Crit Care Med 2000; 161: 1218-1228.

16 Lehtimaki L, Kankaanranta H, Saarelainen S, Turjanmaa V, Moilanen E. Increased alveolar nitric oxide concentration in asthmatic patients with nocturnal symptoms. Eur Respir J 2002; 20: 841-845.

17 Hogman M, Holmkvist T, Wegener T, et al. Extended NO analysis applied to patients with COPD, allergic asthma and allergic rhinitis. Respir Med 2002; 96: 24-30.

18 George SC, Hogman M, Permutt S, Silkoff PE. Modeling pulmonary nitric oxide exchange. J Appl Physiol 2004; 96: 831-839.

19 Silkoff PE, McClean PA, Slutsky AS, et al. Marked flowdependence of exhaled nitric oxide using a new technique to exclude nasal nitric oxide. Am J Respir Crit Care Med 1997; 155: 260-267.

20 Kharitonov SA, Chung FK, Evans DJ, O'Connor BJ, Barnes PJ. The elevated level of exhaled nitric oxide in asthmatic patients is mainly derived from the lower respiratory tract. Am J Respir Crit Care Med 1996; 153: 1773-1780.

21 Kharitonov SA, Yates DH, Robbins RA, Logan-Sinclair R, Shinebourne EA, Barnes PJ. Increased nitric oxide in exhaled air of asthmatic patients. Lancet 1994; 343: 133-135.

22 Lehtimaki L, Kankaanranta H, Saarelainen S, Turjanmaa V, Moilanen E. Inhaled fluticasone decreases bronchial but not alveolar nitric oxide output in asthma. Eur Respir J 2001; 18: 635-639.

23 Brindicci C, Cosio B, Gajdocsi R, et al. Extended exhaled NO measurements at different exhalation flows may differentiate between bronchial and alveolar inflammation in patients with asthma and COPD. Eur Respir J 2002; 20: Suppl. 38, 174s. 
24 Tsoukias NM, George SC. A two-compartment model of pulmonary nitric oxide exchange dynamics. J Appl Physiol 1998; 85: 653-666.

25 Shin HW, Rose-Gottron CM, Cooper DM, Newcomb RL, George SC. Airway diffusing capacity of nitric oxide and steroid therapy in asthma. J Appl Physiol 2004; 96: 65-75.

26 Gelb AF, Taylor CF, Nussbaum E, et al. Alveolar and airway sites of nitric oxide inflammation in treated asthmatics. Am J Respir Crit Care Med 2004.

27 Shin HW, Rose-Gottron CM, Perez F, Cooper DM, Wilson AF, George SC. Flow-independent nitric oxide exchange parameters in healthy adults. J Appl Physiol 2001; 91: 2173-2181.

28 Fabbri LM, Romagnoli M, Corbetta L, et al. Differences in airway inflammation in patients with fixed airflow obstruction due to asthma or chronic obstructive pulmonary disease. Am J Respir Crit Care Med 2003; 167: 418-424.

29 Maestrelli P, Paska C, Saetta M, et al. Decreased haem oxygenase- 1 and increased inducible nitric oxide synthase in the lung of severe COPD patients. Eur Respir J 2003; 21 971-976.

30 van Straaten JF, Postma DS, Coers W, Noordhoek JA, Kauffman HF, Timens W. Macrophages in lung tissue from patients with pulmonary emphysema express both inducible and endothelial nitric oxide synthase. Mod Pathol 1998; 11: 648-655.

31 Tsoukias NM, Shin HW, Wilson AF, George SC. A singlebreath technique with variable flow rate to characterize nitric oxide exchange dynamics in the lungs. J Appl Physiol 2001; 91: 477-487. 